\title{
Work Related Stress among Saudi Nurses Working in Intensive Care Units
}

\author{
Ahmad Batran \\ Faculty of Nursing, Arab American University, Jenin, Palestine \\ Email: ahmad.batran@aaup.edu
}

How to cite this paper: Batran, A. (2019) Work Related Stress among Saudi Nurses Working in Intensive Care Units. Open Journal of Nursing, 9, 1143-1152. https://doi.org/10.4236/ojn.2019.911084

Received: October 2, 2019

Accepted: November 25, 2019

Published: November 28, 2019

Copyright (c) 2019 by author(s) and Scientific Research Publishing Inc. This work is licensed under the Creative Commons Attribution International License (CC BY 4.0).

http://creativecommons.org/licenses/by/4.0/

\begin{abstract}
Background and Aim: Work-Related Stress in nurses is considered a common problem worldwide. Therefore, this study aims to identify the sources of stress among nurses in Saudi Arabia to understand the effect of these stressors on their mental health and physical health. Materials and Methods: A self-administrative questionnaire to assess sources of work stress, physical health, and mental health was administrated to 213 nurses working in intensive care units. Results: The results demonstrated that workload, lack of resources and support, and dealing with death and dying are the principal sources of work's stress. Nurses reported that back pain, headache, and fatigue are the most common health problems while nervousness $(32.4 \%)$ and exhaustion (30\%) were the most frequent mental health problem. Moreover, the results revealed a positive correlation between Work-Related Stress and Health Problems. Conclusion: This study contributes to the emerging body of knowledge about work-related stress in the nursing profession and it is strongly supporting the need for strategic plan and intervention programs to reduce stress symptoms among nurses in Saudi Arabia.
\end{abstract}

\section{Keywords}

Job Stress, Mental Health, Arab Nurses, Stressors

\section{Introduction}

Work-related Stress is a critical issue in all professions. However, Work-Related Stress varies from one profession to another. Previous literature has demonstrated that the prevalence of stress is highly presented in Health Professions [1] [2]. This high level of stress is related to the type of tasks and responsibilities required in this kind of professions. 
Among health practitioners, nurses reported the highest level of stress [3] [4] [5]. Hence, Work-Related Stress in nurses is considered a common problem worldwide [6] [7]. Sources of stress in nurses could vary from country to another. In a cross-cultural study conducted by [8], work-related stress was categorized into culture-specific (emic) and culture-general (etic) stressors. However, work overload was considered as one of the most influential stressors among nurses in all studied countries.

In general, Work-Related Stress could be classified into three major components: Personal variables such as self-confidence and communication skills [9] [10], the occupational variables such as dealing with death and severe injuries [11] [12], and the organizational variables include workload and labour conditions [13]. Work-Related Stress in nursing has associated with a low level of job satisfaction [14], and with a high level of psychological and somatic symptoms [6]. Moreover, exposure to Work-Related Stress had positively correlated with job burnout [15] which leads to reduce the professional quality of life [16]. All these findings confirmed the negative effect of work-related stress on patients, nurses, and the development of the nursing profession around the world.

According to [17], nurses are the largest health care group in the world; nurses and midwives represent about $50 \%$ of the global health workforce. At the same time, the nursing shortage is clearly reported worldwide [18] [19] [20]. This critical problem is considered one of the serious challenges facing nurses in the Arab World [21] [22]. In 2012, there were only 48 nurses and midwives for every 10,000 Saudi Arabia population [23]. In addition to the nursing shortage, nursing profession faces many challenges in Saudi Arabia. In a recent literature review conducted by [24], challenges were classified to structure (e.g., shortage of staff and scope of nursing practice), process (e.g., role of the Clinical Teachers, educational and teaching methods), and outcomes (e.g., assessment of staff competencies).

Considering the socio-cultural context, work stressors and their effect on Health could be different from country to another. However, identifying these stressors could help the policymakers and professionals to develop the nursing profession. Therefore, this study aims to identify the sources of stress among nurses in Saudi Arabia to understand the effect of these stressors on their mental health and physical health.

\section{Methods}

\subsection{Participants}

A purposive sample consisted of 213 nurses, who work in intensive care units or neonatal units invited to participate in this study between June 2017 - June 2018. The inclusion criteria set for sample selection were as follows: Nurses with full-time employment from the intensive care units or neonatal units at King Khalid Hospital, Najran General Hospital, New Najran General Hospital, and King Fahed Medical City. 


\subsection{Instruments}

For data collection, a self-administrative questionnaire was developed by [25] used with permission to assess:

1) Nurses' socio-demographic characteristic as regards their age, gender, educational level, marital status, job position, total experience years and current experience.

2) Sources of work stress as regards dealing with Death and dying, Conflict with physicians, inadequate preparation, Lack of support and resources, Conflict with other nurses, Workload, and Uncertainty concerning treatment. The questions used the 3-point Likert scale from very low stress to high-level stress. The score was calculated for as follows: scores $1=$ low level of stress, scores $2=\bmod -$ erate level of stress and scores $3=$ high level of stress.

3) Physical Health as regard Skin allergy, Pneumonia, Varicose vein, Fatigue, Headache, Fainting, Cramps, Stomachache, Acidity, Decrease in hearing adequacy, and Back pain. The questions used the 2-point dichotomous scale yes or no. The score was given 2 to yes answer and 1 score to no answer.

4) Mental health as regard Exhaustion, Difficulties to concentrate, Insomnia, and Nervousness. The questions used the 3-point Likert scale from very low stress to high-level stress. The score was calculated for as follows: scores $1=$ low level of stress, scores $2=$ moderate level of stress and scores $3=$ high level of stress. The Cronbach's alpha was calculated for this questionnaire with 0.92 which is strongly reliable.

\subsection{Procedure}

This study was approved by the administration of the four selected hospitals. The nurses were informed of the purpose of the study, and that they had the right to refuse to participate. Also, the voluntary nature of participation was stressed as well as confidentiality. Furthermore, the nurses were told that they can refrain from answering any questions and they can terminate at any time. The anonymity of the nurses was maintained at all times. Finally, all participants signed informed consent.

\subsection{Data Analysis}

The quantitative data were entered and analyzed using the SPSS (Statistical Package for Social Sciences, version 23), and the level of significance ( $\alpha$ ) was set at 0.01 . Demographic and baseline variables were analyzed using frequency, percentage, and mean. Analyzing by using t. test and One-Way ANOVA were applied to compare between means of total sources of work-related stress.

\section{Results}

All nurses enrolled in the study completed the demographic data sheet. The majority of the participants were females and staff nurses $(n=192,90.1 \%)$. The most participants age was 30 years or less $(\mathrm{n}=119,55.9 \%)$ and around 132 
(62.0\%) had a nursing bachelor. Around half of the studied sample 107 (50.3\%) was single. More than half of the participants113 $(53.1 \%)$ had past experience between 6 - 15 years and 112 (52.6\%) of nurses had current job experience of more than 5 years as shown in Table 1 .

Results revealed that the workload stress was the highest average scores between sources of the work stress 59.4 (14.67), the second source of work stress was lack of support 55.3 (19.13). On the other hand, conflict with other nurses had the lowest source of work stress 52.5 (16.78) (see Table 2).

One way Anova and $t$ test students were used in order to examine the differences between means in the total of Work Related Stress. Results revealed statistically significant differences $(\mathrm{p}=0.001)$ in job stress sources related to variables of gender, hospitals, past experience, and current job experience (see Table 3 ).

Table 1. Socio-demographic characteristics of the selected sample.

\begin{tabular}{|c|c|c|c|}
\hline Parameters & & $\mathrm{N}$ & $\%$ \\
\hline \multirow[t]{4}{*}{ Age } & $20-30$ years & 119 & 55.9 \\
\hline & $31-40$ years & 76 & 35.7 \\
\hline & $41-50$ years & 16 & 7.5 \\
\hline & $51-60$ years & 2 & 0.9 \\
\hline \multirow[t]{4}{*}{ Hospital } & King Khalid Hospital & 48 & 22.5 \\
\hline & Najran General Hospital & 50 & 23.5 \\
\hline & New Najran General Hospital & 46 & 21.6 \\
\hline & King Fahed medical city & 69 & 32.4 \\
\hline \multirow[t]{2}{*}{ Gender } & Male & 21 & 9.9 \\
\hline & Female & 192 & 90.1 \\
\hline \multirow[t]{3}{*}{ Educational level } & Diploma or less & 79 & 37.1 \\
\hline & Bachelor & 132 & 62.0 \\
\hline & Master & 2 & 9 \\
\hline \multirow[t]{4}{*}{ Job position } & Practical nurse & 7 & 3.3 \\
\hline & Staff nurse & 197 & 92.5 \\
\hline & Head nurse & 9 & 4.2 \\
\hline & Single & 107 & 50.2 \\
\hline \multirow[t]{2}{*}{ Marital status } & Married & 104 & 48.8 \\
\hline & Divorced & 2 & 9 \\
\hline \multirow[t]{3}{*}{ Past Experience } & 5 years or less & 83 & 39.0 \\
\hline & $6-15$ years & 113 & 53.1 \\
\hline & More than 15 years & 17 & 8 \\
\hline \multirow[t]{2}{*}{ Current job experience } & 5 years or less & 101 & 47.4 \\
\hline & more than 5 years & 112 & 52.6 \\
\hline
\end{tabular}


Table 2. Average of work stressors among nurses.

\begin{tabular}{lccc}
\hline & Sources of work stress & Mean & Std. Deviation \\
\hline 1 & Work load & 59.43 & 14.67 \\
2 & Lack of resources and support & 55.32 & 19.13 \\
3 & Dealing with Death and dying & 54.79 & 17.42 \\
4 & Inadequate preparation & 54.57 & 17.43 \\
5 & Uncertainty concerning treatment & 54.17 & 18.17 \\
7 & Conflict with physicians & 52.99 & 16.06 \\
\hline
\end{tabular}

Table 3. Comparison between mean of total sources of Work Related Stress and some characteristics.

\begin{tabular}{|c|c|c|c|c|c|c|}
\hline \multicolumn{2}{|l|}{ Parameters } & \multirow{2}{*}{$\begin{array}{l}\mathrm{n} \\
21\end{array}$} & \multirow{2}{*}{$\begin{array}{l}\mathrm{M} \\
66.23\end{array}$} & \multirow{2}{*}{$\begin{array}{l}\text { SD. } \\
10.88\end{array}$} & \multirow{2}{*}{$\begin{array}{l}t / F \\
10.6\end{array}$} & \multirow{2}{*}{$\begin{array}{l}P_{\text {value }} \\
0.001\end{array}$} \\
\hline Gender & Male & & & & & \\
\hline & Female & 192 & 56.91 & 12.63 & & \\
\hline \multirow[t]{4}{*}{ Age } & 20 - 30 years & 119 & 56.89 & 12.88 & & \\
\hline & $31-40$ years & 76 & 60.02 & 12.67 & 1.3 & 0.270 \\
\hline & $41-50$ years & 16 & 54.88 & 12.16 & & \\
\hline & $51-60$ years & 2 & 53.79 & 4.29 & & \\
\hline \multirow[t]{4}{*}{ Hospital } & King Khalid Hospital & 48 & 48.99 & 10.899 & & \\
\hline & Najran General Hospital & 50 & 67.20 & 5.519 & 27.0 & 0.001 \\
\hline & New Najran General Hospital & 46 & 53.05 & 13.16 & & \\
\hline & King Fahed medical city & 69 & 60.38 & 12.13 & & \\
\hline \multirow[t]{3}{*}{ Marital status } & Single & 107 & 57.10 & 12.25 & & \\
\hline & Married & 104 & 58.43 & 13.34 & 0.7 & 0.484 \\
\hline & Divorced & 2 & 66.29 & 2.68 & & \\
\hline \multirow[t]{3}{*}{$\begin{array}{l}\text { Educational } \\
\text { level }\end{array}$} & Diploma Nurse & 79 & 60.64 & 11.48 & 3.1 & 0.046 \\
\hline & Bachelor Level & 132 & 56.16 & 13.308 & & \\
\hline & Master & 2 & 56.82 & 6.43 & & \\
\hline \multirow[t]{3}{*}{ Job position } & Practical nurse & 7 & 55.30 & 12.27 & & \\
\hline & Staff nurse & 197 & 57.88 & 12.85 & 0.2 & 0.855 \\
\hline & Head nurse & 9 & 58.67 & 12.22 & & \\
\hline \multicolumn{2}{|c|}{ Past Experience 5 years or less } & 83 & 53.82 & 12.99 & & \\
\hline & $6-15$ years & 113 & 60.00 & 11.51 & 7.5 & 0.001 \\
\hline & More than 15 years & 17 & 62.97 & 14.83 & & \\
\hline \multirow[t]{2}{*}{$\begin{array}{l}\text { Current job } \\
\text { experience }\end{array}$} & 5 years or less & 101 & 54.41 & 13.48 & 14.7 & 0.001 \\
\hline & more than 5 years & 112 & 60.91 & 11.26 & & \\
\hline
\end{tabular}


Results in Table 4 showed that the most common physical health problems were back pain and headache $152(71.4 \%)$ and 148 (69.5\%) respectively while pneumonia $56(26.3 \%)$ and decrease in hearing adequacy $31(21.5 \%)$ were less frequent among nurses.

Regarding the common psychological problems related to stressors, findings demonstrated that nervousness was the highest mental health problem among nurses 69 (32.4\%) while exhaustion was the second one 64 (30.0\%). At the same time, difficulties to concentrate were the lowest one at 50 (23.5\%). See Table 5.

Results revealed that there were statistically significant differences between mean of mental health problems according to hospitals $(\mathrm{F}(208)=30.260, \mathrm{p}=$ $0.001)$, and current job experience $(F(210)=8.325, p=0.004)$. See Table 6 .

Finally, Results showed that there is a moderate correlation between mental health problems and job stress $(\mathrm{r}=0.448, \mathrm{p}=0.001)$. See Table 7 .

Table 4. Number \& percent distribution of nurses' physical health problem $(\mathrm{N}=213)$.

\begin{tabular}{cccc}
\hline & Physical health & $\mathrm{n}$ & $\%$ \\
\hline 1 & Back pain & 152 & 71.4 \\
2 & Headache & 148 & 69.5 \\
3 & Fatigue & 139 & 65.3 \\
4 & Varicose vein & 105 & 49.3 \\
5 & Acidity & 106 & 49.8 \\
6 & Stomachache & 92 & 43.2 \\
7 & Cramps & 95 & 44.6 \\
8 & Skin allergy & 101 & 47.4 \\
9 & Fainting & 72 & 33.8 \\
10 & Pneumonia & 56 & 26.3 \\
11 & Decrease in hearing adequacy & 48 & 22.5 \\
\hline
\end{tabular}

Table 5. Distribution of nurses' mental health problems related to stressors.

\begin{tabular}{ccccccc}
\hline Parameters & \multicolumn{2}{c}{ Low } & \multicolumn{2}{c}{ Moderate } & \multicolumn{2}{c}{ Severe } \\
\hline & n. & $\%$ & $\mathrm{~N}$ & $\%$ & $\mathrm{n}$ & $\%$ \\
\hline Nervousness & 76 & 35.7 & 68 & 31.9 & 69 & 32.4 \\
Insomnia & 69 & 32.4 & 83 & 39.0 & 61 & 28.6 \\
Exhaustion & 56 & 26.3 & 93 & 43.7 & 64 & 30.0 \\
Difficulties to concentrate & 66 & 31.0 & 97 & 45.5 & 50 & 23.5 \\
\hline
\end{tabular}

Table 6. Differences between demographic characteristics and mental health problems related to stressors.

\begin{tabular}{lllllll}
\hline Parameters & & $\mathrm{n}$ & $\mathrm{M}$ & $\mathrm{SD}$. & $\mathrm{t} / \mathrm{F}$ & $P$ value \\
\hline \multirow{2}{*}{ Gender } & Male & 21 & 2.0833 & 0.64388 & 0.791 & 0.436 \\
& Female & 191 & 1.9660 & 0.65556 & & \\
\hline
\end{tabular}




\section{Continued}

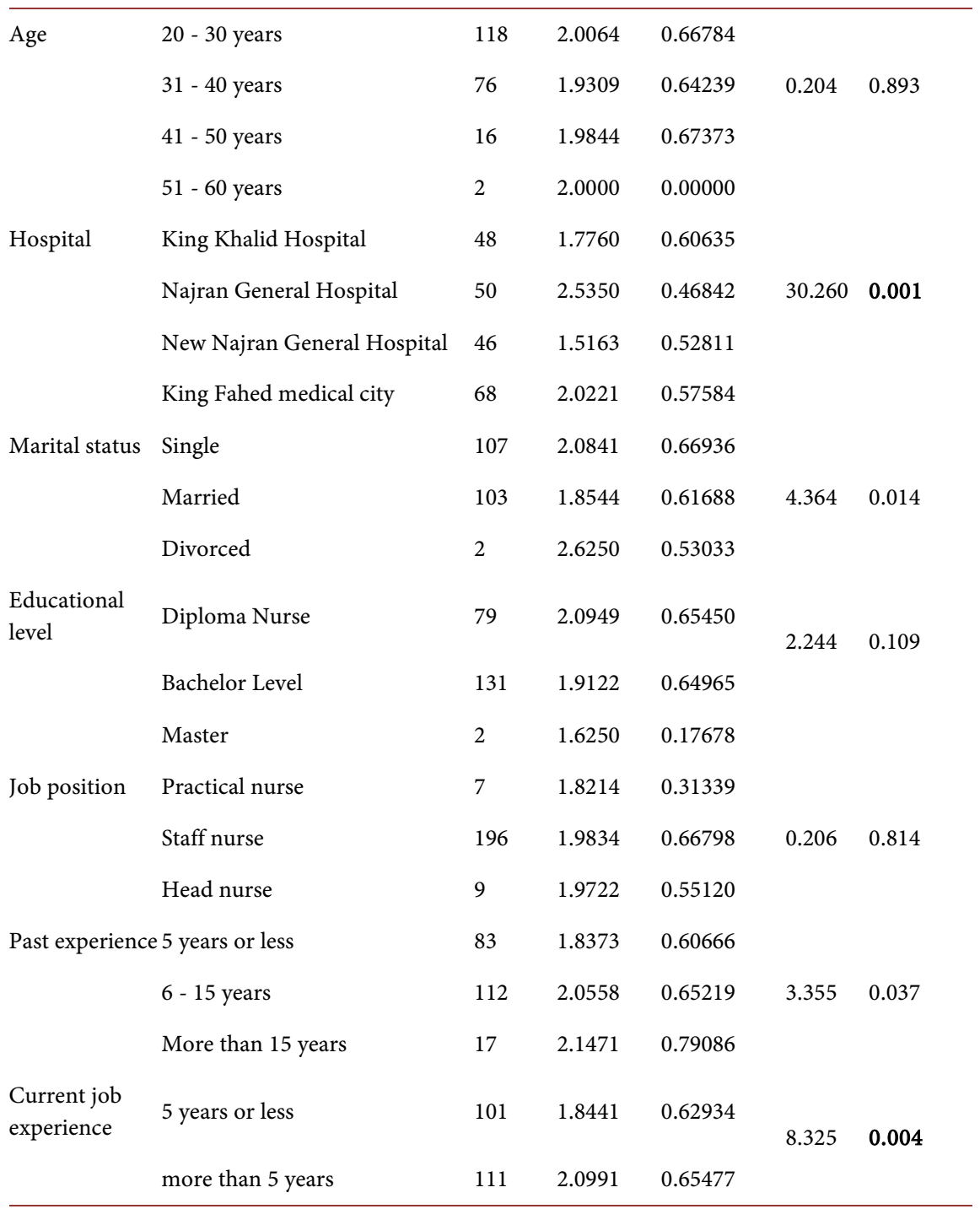

Table 7. Relationship between mean of total mental health problems and Job stress factors $(\mathrm{N}=213)$.

\begin{tabular}{ccc}
\hline Parameters & $\mathrm{R}$ & $P_{\text {value }}$ \\
\hline Job stress and mental health problems & 0.448 & $\mathbf{0 . 0 0 1 * *}^{* *}$
\end{tabular}

** Correlation is significant at the 0.001 level (2-tailed).

\section{Discussion}

The main objective of this study was to identify the sources of stress among nurses in Saudi Arabia. The results demonstrated that workload, lack of resources and support, and dealing with death and dying are the principal sources of work's stress. In physical health, back pain, headache, and fatigue are the most common health problems reported by nurses themselves. Moreover, nervousness $(32,4 \%)$ and exhaustion (30\%) were the most common mental health problem among nurses participated in this study. Finally, Findings confirmed 
the positive correlation between Work-Related Stress and Health Problems. In general, exposure to more Work Stressors increases the possibility of developing health problems. Nevertheless, this relationship is depending on variables related to the type of stressors, its intensity, and person resilience [26].

Concerning the sources of work stress, the results of this study coincide with previous studies in that workload and lack of resources and support represents the main sources of work stress among nurses [25] [27]. This could be explained by the large nursing shortage worldwide [19]. In Saudi Arabia, the limited number of nurses working in the Hospital led them to work extra hours. Although the nursing profession has been developed in the Arab World as well as Saudi Arabia in recent years, the lack of resources and support still considered as one of the major stressors [28]. These results are also consistent with [8] who found that lack of recourses is the highest stressors among nurses in Hungary and one of the most stressors among nurses in several countries. Furthermore, some occupational tasks represent another source of stress for nurses, and dealing with death was considered one of the most significant sources of stress. This type of tasks increases the possibility to develop symptoms of stress among nurses [29].

In this study, differences in identifying the sources of work stress in this study were related to gender, location of the hospitals, and past and current job experiences. Males have obtained a higher score than females in the total score of stress resources in the work. Organizational conditions, current experience, and past experience were important in determining the total scores of Work-Related Stresses. However, Findings revealed that developing psychological problems are depending on the location of the hospitals and current job experience. This means that both personal and organizational factors mediate the relationship between exposure to stress sources and developing stress symptoms. Our findings demonstrated that nurses with more than 5 years of experiences demonstrated a high level of psychological and somatic complains compared to those who have less experience. These results are in accordance with previous work conducted in Arabia Saudi where they found that the level of stress has increased among nurses with more years of professional experience [30].

It is important to mention certain limitations that restrain the scope of this study. The selected sample from Riyadh and Najran limits the data's generalization. Moreover, the lack number of males among participation limits the study of gender differences. For futures studies, it may be interesting to extend this study to more Arab countries. Despite these limitations, this study contributes to the emerging body of knowledge about Work-Related Stress in the nursing profession. Our findings strongly support the need for strategic plan and intervention programs to reduce stress symptoms among nurses in Saudi Arabia.

\section{Conflicts of Interest}

The author declares no conflicts of interest regarding the publication of this paper. 


\section{References}

[1] Antoniou, A.S.G., Davidson, M.J. and Cooper, C.L. (2003) Occupational Stress, Job Satisfaction and Health State in Male and Female Junior Hospital Doctors in Greece. Journal of Managerial Psychology, 18, 592-621. https://doi.org/10.1108/02683940310494403

[2] Lu, H., Barriball, K.L., Zhang, X. and While, A.E. (2012) Job Satisfaction among Hospital Nurses Revisited: A Systematic Review. International Journal of Nursing Studies, 49, 1017-1038. https://doi.org/10.1016/j.ijnurstu.2011.11.009

[3] Wilkins, K. (2007) Work Stress among Health Care Providers. Health Reports, 18, 33-36.

[4] Butterworth, T., Carson, J., Jeacock, J., White, E. and Clements, A. (1999) Stress, coping, Burnout and Job Satisfaction in British Nurses: Findings from the Clinical Supervision Evaluation Project. Stress Medicine, 15, 27-33. https://doi.org/10.1002/(SICI)1099-1700(199901)15:1<27::AID-SMI782>3.3.CO;2-L

[5] Wolfgang, A.P. (1988) Job Stress in the Health Professions: A Study of Physicians, Nurses, and Pharmacists. Behavioral Medicine, 14, 43-47. https://doi.org/10.1080/08964289.1988.9935123

[6] Kawano, Y. (2008) Association of Job-Related Stress Factors with Psychological and Somatic Symptoms among Japanese Hospital Nurses: Effect of Departmental Environment in Acute Care Hospitals. Journal of Occupational Health, 50, 79-85. https://doi.org/10.1539/joh.50.79

[7] McCarthy, V.J., Power, S. and Greiner, B.A. (2010) Perceived Occupational Stress in Nurses Working in Ireland. Occupational Medicine, 60, 604-610. https://doi.org/10.1093/occmed/kqq148

[8] Glazer, S. and Gyurak, A. (2008) Sources of Occupational Stress among Nurses in Five Countries. International Journal of Intercultural Relations, 32, 49-66. https://doi.org/10.1016/j.ijintrel.2007.10.003

[9] Emold, C., Schneider, N., Meller, I. and Yagil, Y. (2011) Communication Skills, Working Environment and Burnout among Oncology Nurses. European Journal of Oncology Nursing, 15, 358-363. https://doi.org/10.1016/j.ejon.2010.08.001

[10] Lambert, V.A., Lambert, C.E., Petrini, M., Li, X.M. and Zhang, Y.J. (2007) Workplace and Personal Factors Associated with Physical and Mental Health in Hospital Nurses in China. Nursing \& Health Sciences, 9, 120-126. https://doi.org/10.1111/j.1442-2018.2007.00316.x

[11] Tyler, P.A. and Ellison, R.N. (1994) Sources of Stress and Psychological Well-Being in High-Dependency Nursing. Journal of Advanced Nursing, 19, 469-476. https://doi.org/10.1111/j.1365-2648.1994.tb01109.x

[12] Tyson, P.D. and Pongruengphant, R. (2004) Five-Year Follow-up Study of Stress among Nurses in Public and Private Hospitals in Thailand. International Journal of Nursing Studies, 41, 247-254. https://doi.org/10.1016/S0020-7489(03)00134-2

[13] Sveinsdottir, H., Biering, P. and Ramel, A. (2006) Occupational Stress, Job Satisfaction, and Working Environment among Icelandic Nurses: A Cross-Sectional Questionnaire Survey. International Journal of Nursing Studies, 43, 875-889. https://doi.org/10.1016/j.ijnurstu.2005.11.002

[14] Khamisa, N., Oldenburg, B., Peltzer, K. and Ilic, D. (2015) Work Related Stress, Burnout, Job Satisfaction and General Health of Nurses. International Journal of Environmental Research, 12, 652-666. https://doi.org/10.3390/ijerph120100652

[15] Smith, T.D., Hughes, K., DeJoy, D.M. and Dyal, M.A. (2018) Assessment of Rela- 
tionships between Work Stress, Work-Family Conflict, Burnout and Firefighter Safety Behavior Outcomes. Safety Science, 103, 287-292. https://doi.org/10.1016/j.ssci.2017.12.005

[16] Hamaideh, S.H. (2011) Occupational Stress, Social Support, and Quality of Life among Jordanian Mental Health Nurses. Issues in Mental Health Nursing, 33, 15-23. https://doi.org/10.3109/01612840.2011.605211

[17] World Health Organization (2018) Fact Sheet: Nursing and Midwifery. https://www.who.int/news-room/fact-sheets/detail/nursing-and-midwifery

[18] Allen, L. (2008) The Nursing Shortage Continues as Faculty Shortage Grows. Nursing Economics, 26, 35-41.

[19] Chan, Z.C., Tam, W.S., Lung, M.K., Wong, W.Y. and Chau, C.W. (2013) A Systematic Literature Review of Nurse Shortage and the Intention to Leave. Journal of Nursing Management, 21, 605-613. https://doi.org/10.1111/j.1365-2834.2012.01437.x

[20] Leung, P.P., Wu, C.H., Kwong, C.K. and Ching, W.K. (2019) Nursing Shortage in the Public Healthcare System: An Exploratory Study of Hong Kong. Enterprise Information Systems, 50, 1-19. https://doi.org/10.1080/17517575.2019.1569264

[21] Aboshaiqah, A. (2016) Strategies to Address the Nursing Shortage in Saudi Arabia. International Nursing Review, 63, 499-506. https://doi.org/10.1111/inr.12271

[22] Shukri, R. (2005) Status of Nursing in the Arab World. Ethnicity \& Disease, 15, S1-88-9.

[23] World Health Organization (2016) Global Health Observatory-Saudi Arabia. https://apps.who.int/iris/bitstream/handle/10665/136842/ccsbrief_sau_en.pdf?seque $\underline{\text { nce }=1}$

[24] Harb, A. (2019) Current Challenges Facing Nursing Education in Saudi Arabia. Ethnicity \& Disease, 2, 45-50.

[25] Ayed, A., Eqtait, F., Fashafsheh, I., Basheer, M., Aqel, M., Nassar, D.A. and Omary, M. (2014) Exploring the Work-Related Stress Sources and Its Effect among the Palestinian Nurses at the Governmental Hospitals. Jersey Evening Post, 5, 100-110.

[26] Guo, Y.F., Luo, Y.H., Lam, L., Cross, W., Plummer, V. and Zhang, J.P. (2018). Burnout and Its Association with Resilience in Nurses: A Cross-Sectional Study. Journal of Clinical Nursing, 27, 441-449. https://doi.org/10.1111/jocn.13952

[27] Chang, E.M., Hancock, K.M., Johnson, A., Daly, J. and Jackson, D. (2005) Role Stress in Nurses: Review of Related Factors and Strategies for Moving forward. Nursing \& Health Sciences, 7, 57-65. https://doi.org/10.1111/j.1442-2018.2005.00221.x

[28] Almalki, M., Fitzgerald, G. and Clark, M. (2011) Health Care System in Saudi Arabia: An Overview. Eastern Mediterranean Health Journal La Revue de Santé dela Méditerranée orientale, 17, 784-793. https://doi.org/10.26719/2011.17.10.784

[29] Dagget, T., Molla, A. and Belachew, T. (2016) Job Related Stress among Nurses Working in Jimma Zone Public Hospitals, South West Ethiopia: A Cross Sectional Study. BMC Nursing, 15, 39. https://doi.org/10.1186/s12912-016-0158-2

[30] Al Shehri, B., Al Shimemeri, S. and Al Aomry, A. (2012) Factors Leading to Stress among Saudi Nurses. Middle East Journal of Psychiatry and Alzheimer's, 3, 17-22. 